\title{
School catering: the place for change?
}

\author{
Susan C. Collins* \\ S.R.D., M.H.C.I.M.A. \\ ILEA Education Catering Branch
}

\begin{abstract}
Summary
The 1944 Education Act marked the foundation of the modern School Catering Service. A statutory duty is imposed on Local Education Authorities (LEAs) to provide a 'mid-day dinner ... suitable in all respects as the main meal of the day'. LEAs are free to provide meals consistent with broad nutritional guidelines of the Department of Education and Science but financial pressures have a large bearing on this. The traditional 2-course meal is still the norm, although there is a multi-choice menu for the majority of secondary schoolchildren. But a wide choice of food is incompatible with closely prescribed nutritional standards and pupils need to be aware of the implications for their health in the choice of food. The adoption of dietary recommendations for prevention of coronary heart disease would not generate serious practical difficulties for the professional caterer. The technical problems arising from minor adaptations in catering practice would be minimal in comparison to those of cost, education and hence modification of consumer demand. The move away from nutritional standards is likely to accelerate if, owing to financial constraints, the Government withdraws nutritional guidelines or removes the obligation on LEAs to provide a catering service. The danger is that financial considerations will override those of nutrition and a unique opportunity for health education by guidance and example in the schools may be lost.
\end{abstract}

Origins and development of the School Meals Service

The Lancet precipitated an outcry in Parliament in 1870 when it carried an article which argued: 'The Education system is not overworking children but demonstrating that they are underfed.' (Evans, 1974). This did not produce any legislation but it did excite various voluntary bodies into providing schoolchildren with something to eat. A typical week's menu was: Monday, jam pudding; Tuesday, thick meat soup; Wednesday, rhubarb pudding; Thursday, roly-poly meat pudding; Friday, raisin pudding; each portion to be $0.5-0.75 \mathrm{lb}(0.225-0.34$ kg).

The last 100 years have certainly witnessed change. The first legislation relating to School Meals came

*The views expressed are the personal ones of the author, and not those of her organization. in 1906 , but it was the 1944 Education Act which marked the foundation of the present School Meals Service. This Act imposes on LEAs a statutory duty to provide school dinners for all maintained primary and secondary school pupils who want them. Since the Act was implemented there have been nutritional principles underlying school meals feeding.

The current Provision of Milk and Meals Regulations state: 'On every school day there shall be provided ... for every pupil as a mid-day dinner a meal suitable in all respects as the main meal of the day' (Statutory Instrument, 1969).

The Regulations do not specify what constitutes a 'suitable mid-day meal' but in 1975 a Working Party Report, 'Nutrition in Schools', was published by the Department of Education and Science (DES 1975). This provides the current documentation upone which the nutritional standards for school meals are based and states: 'The average school meal... should aim to provide at minimum one-third of the recommended intake of energy, and between half and one-third (say $42 \%$ ) of the recommended intake for protein' (DES, 1975, p. 12). 'A mixed diet of animal and vegetable foods should provide all the necessary nutrients ...' (DES, 1975, p. 13).

The Report recommends that the minimum amount of fat to be provided by a school meal should no longer be specified, the implication being that fat should be restricted. The Working Party reported that the possible relationship between consumption of saturated fat and the incidence of heart disease: '. . . is widely discussed but has not been established. In view of the present uncertainty we do not feel able to suggest that the use of animal fats should be reduced on health grounds' (DES, 1975, p. 14).

Sugar consumption is mentioned only in relation to the effect on dental health: '... for many years sugar has been used sparingly in the preparation of the school dinner and the present recommended quantity of half an ounce per meal is probably no more than is necessary to make the meal appetizing. We consider that this quantity should not on average be exceeded' (DES, 1975, p. 18).

There are no recommendations pertaining to the fibre or salt content of school meals.

LEAs are free to plan meals within the limits of 
the DES regulations. Reconciliation of nutritional standards with financial constraints requires skill and ingenuity on the part of the caterer. Although the charge for a school meal is $30 \mathrm{p}$, the food allowance is, on average, $18 \mathrm{p}$ a head.* The result has been one of variety in the types of meal provided in different parts of the country. It is common for menus to be planned by individual Heads of Kitchen in accordance with LEA policy. In a few Authorities, menu planning and provisioning are centralized and computerized, despite the associated problems of inflexibility.

It is generally accepted that choice meals are inappropriate for the very young. Most infant and nursery schools, therefore, are given 2-course set menus. Junior schoolchildren are normally offered a limited choice of 2 main dishes and a salad meal, 2 vegetables, potato or alternative, and 2 desserts. Multi-choice menus are offered in the majority of secondary schools and it is becoming increasingly common to find salad bars, snack items, and cash cafeteria systems. The aim is to provide the widest range consistent with financial limitations and good nutritional practice in the hope that children will make sensible choices.

A free choice, albeit from a selection of controlled items, is incompatible with the imposition of closely prescribed nutritional standards. This begs the question-has the concept of nutritional standards for school means become out-dated? It is argued that it has not, since to remove nutritional standards would lead to financial considerations becoming overriding. This could be at the expense of any nutritional conscience in the feeding of 5 million schoolchildren. Nutritional parameters should not be ignored-at the very least there ought to be a moral constraint.

\section{Proposals for new legislation and potential influence on school catering}

The Government's recent financially based proposals for new legislation on school catering may abolish the statutory requirement for LEAs to provide a mid-day meal. Some Authorities may recognize the need for a School Catering Serviceand be prepared to pay for it. Others may not. In order to give more freedom to those Authorities which choose to maintain a catering service, the new legislation may withdraw recommendations which, since 1944, have laid down the nutritional content of the meal. Ironically, it has always been the nutritional standard, based on sound physiological principles, which has protected the school meal in times of previous financial stringency.

The climate of change with its consequent problems and opportunities is greater than ever * November 1979 before in the life of the School Meals Service. In those LEAs which decide to continue to provide schoolchildren with a catering service, fundamental decisions will have to be taken.

\section{Possibilities for the future}

If the DES is to relinquish its responsibilities towards school catering, LEAs will become dependent entirely on local expertise and experience. There is a well established, managerial staff of professional caterers, the School Meals Organizers, who advise Authorities and control the Heads of Kitchen. The availability and quality of such expertise and experience varies, and consequently the emphasis attached to the nutritional content of the fare provided. There will be more opportunity than ever for health professionals, particularly District and Community Dietitians, to offer sound, practical advice to their catering colleagues. This may not be easy, as indicated by an opinion column in a recent edition of a catering journal: 'Arguments over the need to ensure the correct content of the diet are falling on ears more attuned to the ringing of cash registers, as Councils face bigger deficits brought about by school meals subsidies. Besides, the validity of dietary arguments is difficult to gauge when nutritionists seem unable to agree among themselves on what is good or bad for us' (Editorial, 1979).

This reinforces the author's concern about financial considerations dominating school catering - the 'commercial approach'. Any successful catering operation must be financially viable but costeffectiveness and sound nutritional practice do not have to be mutually exclusive. If, to some LEAs they appear to conflict, then in the current climate financial considerations may outweigh those of nutrition. Some Authorities may merely hand over to contract caterers.

Regrettably some nutritionally favoured commodities are incompatible with prices the consumer is prepared to pay. Wholemeal breads and pastas are more expensive than white. Polyunsaturated margarines and cooking oils are more expensive than saturated equivalents. Lean meats are more expensive than constituted products such as sausages and luncheon meat. Fresh fruit is, for much of the year, more expensive than the ingredients for traditional puddings. This situation is a reflection of lack of nutritional awareness leading to low demand, and hence relatively high prices. Consumer demand has a controlling effect on the menus compiled by the caterer. Children will choose food they enjoy rather than food best for their health and the concept of enjoyment is immediate, whereas the concept of good health is abstract and long term.

There is a need to reconcile advice from the medical profession on healthy eating and the caterer's 
task of providing dishes attractive to the customer and at a competitive price. Otherwise children will fill themselves at the school tuck-shop or patronize the local 'chippy'. If the School Catering Service was still providing standard no-choice meals, the emphasis on education for healthy eating could be directed to the professional caterer. Now that there is certain to be even more degeneration from set or limited-choice menus having some basis of nutritional control, to a much freer choice system, a parallel target for nutrition education must be the consumer. Where better to introduce education about food but in school? The methodology is not within the scope of this paper but merely imparting knowledge is not sufficient. To be effective the result has to be behaviour modification. Ultimately, the criteria which determine what the school caterer provides is what the pupil is prepared to eat and pay for. Otherwise the caterer will go out of business.

This does not mean that school caterers should neglect nutritional aspects of catering. Children usually take only one meal a day at school, for about $\mathbf{2 0 0}$ days a year, but for many children this represents the main meal of the day and the only meal based on sound nutritional principles. For such children, the school meal provides a significant proportion of nutrient intake, perhaps the only intake of certain essential nutrients. The school caterer is in a strong position to exert considerable influence on the eating habits of children by setting good examples-both in menu compilation and in the standard of cooking and service.

There are challenging opportunities for collaboration between those responsible for school catering and educationists. Measures combining learning activities and good food provision, including the introduction of new organoleptic experiences, can be instrumental in the development of healthy eating habits-not only during school years but for a lifetime. If the school sees its role as education for living, as well as education for working, then an assessment of its attitude towards the food it makes available is warranted.

But if we expect caterers to demonstrate good nutritional principles, then those concerned with nutrition must be prepared to give them concise advice on fundamental issues, and eliminate contentious details which lead only to confusion.
To refer to the catering article quoted above: '... the validity of dietary arguments is difficult to gauge when nutritionists seem unable to agree among themselves on what is good or bad for us'.

Practical implications for the adoption of recommendations for dietary prevention of coronary heart disease

As long as the caterer is advised clearly there should be no significant problems in providing palatable food consistent with preventive recommendations. Any consequent change in long established catering practice will bring with it a requirement for appropriate training, and that will take time and cost money. But in adopting dietary recommendations, in the author's opinion, the difficulty is not one of manipulating raw foodstuffs in the kitchen. The technical problems of catering would be minor in comparison with the other problems discussed-those of cost and availability, and those of education (of the caterer and the consumer) and hence modification of consumer demand.

Major problems such as these are overshadowed by the current threat to the School Catering Service Within the present structure, the largest catering concern in the country, there is the facility for health education and central nutritional control. This is not to suggest that school catering could solve all nutritional problems. But if it is accepted that longterm improvement of nutritional status lies with children, the Government should reconsider their proposals. If the statutory duty on LEAs to provide the present level of service is removed, and if DES guidelines are no longer applied to whatever service remains, then a major channel for effecting the proposals of this Conference, as far as children are concerned, will have been swept away.

\section{References}

Department of Education AND Science (1975) Nutrition in Schools. H.M. Stationery Office, London.

EDITORIAL (1979) Opinion column. Caterer and Hotel Keeper, 170, 3.

Evans, J. (1974) Catering in Schools and Colleges, p. 16, Barrie and Jenkins, London.

StatuTORY INSTRUMENT (1969) No. 483: The Provision of Milk and Meals Regulations. Education, England and Wales, p. 2. H.M. Stationery Office, London. 